\title{
Fatty acid and phospholipid chlorohydrins cause cell stress and endothelial adhesion ${ }^{\star}$
}

\author{
Gary Dever, Cherry L. Wainwright ${ }^{1}$, Simon Kennedy ${ }^{2}$ and Corinne M. Spickett ${ }^{\bowtie}$ \\ Institute of Pharmacy and Biomedical Sciences, University of Strathclyde, Glasgow, UK; \\ 凶e-mail: c.m.spickett@strath.ac.uk
}

Received: 17 October, 2006; revised: 13 November, 2006; accepted: 16 November, 2006 available on-line: 27 November, 2006

\begin{abstract}
The oxidation of low-density lipoprotein (LDL) is thought to contribute to atherogenesis, which is an inflammatory disease involving activation of phagocytic cells. Myeloperoxidase, an enzyme which is able to produce hypochlorous acid ( $\mathrm{HOCl})$, is released from these phagocytic cells, and has been found in an active form in atherosclerotic plaques. $\mathrm{HOCl}$ can oxidize both the lipid and protein moiety of LDL, and HOCl-modified LDL has been found to be pro-inflammatory, although it is not known which component is responsible for this effect. As $\mathrm{HOCl}$ can oxidize lipids to give chlorohydrins, we hypothesized that phospholipid chlorohydrins might have toxic and pro-inflammatory effects. We have formed chlorohydrins from fatty acids (oleic, linoleic and arachidonic acids) and from phospholipids (stearoyl-oleoyl phosphatidylcholine, stearoyl-linoleoyl phosphatidylcholine and stearoyl-arachidonoyl phosphatidylcholine), and investigated various biological effects of these oxidation products. Fatty acid and phospholipid chlorohydrins were found to deplete ATP levels in U937 cells in a concentration-dependent manner, with significant effects observed at concentrations of $25 \mu \mathrm{M}$ and above. Low concentrations $(25 \mu \mathrm{M})$ of stearoyl-oleoyl phosphatidylcholine and stearoyl-arachidonoyl phosphatidylcholine chlorohydrins were also found to increase caspase-3 activity. Finally, stearoyl-oleoyl phosphatidylcholine chlorohydrin increased leukocyte adhesion to artery segments isolated from C57B1/6 mice. These results demonstrate potentially harmful effects of lipid chlorohydrins, and suggest that they may contribute to some of the pro-inflammatory effects that HOCl-modified low density lipoprotein has been found to induce.
\end{abstract}

Keywords: chlorinated phospholipids, chlorinated fatty acids, ATP depletion, atherosclerosis, leukocyte adhesion

\section{INTRODUCTION}

Atherosclerosis is now considered as an inflammatory condition, involving immune cell activation and infiltration into the intima, together with increased infiltration of low density lipoprotein (Ross, 1993; Madamanchi et al., 2005). It is also well established that the oxidation of low density lipoprotein (LDL) is a key risk factor for atherosclerosis (Witztum \& Steinberg, 1991), and that oxidized LDL (oxLDL) can contribute to the disease pathology via several different mechanisms. One way that LDL can be oxidized is by the action of the phagocyte enzyme myeloperoxidase, which produces $\mathrm{HOCl}$, among other oxidants. There is now very strong evidence for the involvement of myeloperoxidase in atherosclerosis (Podrez et al., 2000; Brennan \& Hazen, 2003). Early research showed that myeloperoxidase is present in an active form in atherosclerotic lesions (Daugherty et al., 1994), and HOCl-modified epitopes of LDL were detected in lesions using a specific monoclonal antibody (Hazell \& Heinecke, 1997). It was also found that chlorotyrosine derivatives, which are considered to be markers of mye-

\footnotetext{
^ This work was reported at the Polish Biochemical Society Meeting (2006) in Bialystok.

${ }^{1}$ Current address: School of Pharmacy, The Robert Gordon University, Aberdeen, UK.

${ }^{2}$ Current address: Institute of Biomedical and Life Sciences, Glasgow University, Glasgow, UK.

Abbreviations: AA, arachidonic acid; $\mathrm{HOCl}$, hypochlorous acid; LA, linoleic acid; LDL, low density lipoprotein; MCP-1, monocyte chemotactic protein-1; MPO, myeloperoxidase; OA, oleic acid; PMSF, phenylmethylsulfonyl fluoride; SAPC, stearoyl-arachidonoyl phosphatidylcholine; SLPC, stearoyl-linoleoyl phosphatidylcholine; SOPC, stearoyl-oleoyl phosphatidylcholine.
} 
loperoxidase activity, have been detected at various stages of lesion development and are elevated in LDL and HDL isolated from atherosclerotic lesions (Hazen \& Heinecke, 1997; Bergt et al., 2004). Chlorinated lipids, in the form of $\alpha$-chloro fatty aldehydes, have also been detected in atherosclerotic plaque samples (Thukkani et al., 2003). As well as products of myeloperoxidase and $\mathrm{HOCl}$ attack, the free $\mathrm{HOCl}$ concentration may reach high concentrations in inflammatory sites, with one study estimating concentrations in the region of $300 \mu \mathrm{M}$ (Katrantzis et al., 1991).

$\mathrm{HOCl}$ is an oxidizing and chlorinating compound that is able to attack many biological molecules. When incubated with low density lipoprotein, it causes both protein oxidation, of which lysine and cysteine residues react particularly readily, and lipid oxidation and peroxidation (Hazell et al., 1997; Carr et al., 2000). The main reaction of $\mathrm{HOCl}$ with unsaturated fatty acyl chains is the formation of chlorohydrins (Winterbourn et al., 1992), and it is known that treatment of isolated human LDL with either $\mathrm{HOCl}$ or myeloperoxidase, at concentrations similar to those thought to occur in atherosclerotic lesions, results in generation of phospholipid chlorohydrins (Jerlich et al., 2000). It has been found that HOCloxidized LDL has some pro-inflammatory effects, such as induction of the chemotactic cytokine IL-8 in human monocytes and stimulation of neutrophil chemotaxis (Woenckhaus et al., 1998), activation of the NADPH oxidase in macrophages derived from THP-1 and U937 cells (Nguyen-Khoa et al., 1999), and enhanced adhesion of polymorphonuclear leukocytes to human umbilical vein endothelial cells (Kopprasch et al., 1998). For some effects of HOClmodified LDL, it has been suggested that they are mediated via oxidation of the protein moiety (Nguyen-Khoa et al., 1999), but there is still considerable doubt for other effects, and overall the precise modifications and mechanisms responsible have not been identified.

As it is known that free radical oxidized phospholipids have a variety of pro-inflammatory effects (Watson et al., 1997; Subbanagounder et al., 2002a; Spickett \& Dever, 2005), and lipid chlorohydrins have previously been found to cause cell lysis, toxicity, and loss of muscle tension (Carr et al., 1997; Iwase et al., 1997; Vissers et al., 2001), we hypothesized that phospholipids and fatty acid chlorohydrins could contribute to deleterious and pro-inflammatory effects of $\mathrm{HOCl}$-modified LDL. In a previous study we had found that phospholipid chlorohydrins caused toxicity to HL60 cells similar to that observed following treatment with autooxidized palmitoyl-arachidonoyl phosphatidylcholine and the lipid peroxidation product 4-hydroxynonenal (Dever et al., 2003). Here we have extended the study to look at the effects of fatty acid chlorohydrins and phospholipid chlorohydrins on U937 cell ATP levels and caspase- 3 activation, and have investigated whether phospholipid chlorohydrins can induce endothelial-leukocyte adhesion, which is an early event in atherosclerotic plaque formation.

\section{MATERIALS AND METHODS}

C57Bl/6 (Harlan, UK Ltd) mice were bred inhouse at the University of Strathclyde under a project licence authorised under the UK Animals (Scientific Procedures) Act. All phospholipids and fatty acids were purchased from Sigma-Aldrich Chemical Company (Poole, UK), and were prepared individually in chloroform at a concentration of $10 \mathrm{mg} / \mathrm{mL}$. The myeloid cell line U937 was obtained from the European Collection of Animal Cell Cultures (UK).

Preparation of chlorohydrins. Aliquots of each lipid were dried under nitrogen and reconstituted by whirlimixing in an equal volume of Hanks buffered saline solution (HBSS), followed by sonication at $35^{\circ} \mathrm{C}$ for $15 \mathrm{~min}$, to form lipid vesicles. The vesicles were treated with a 10 -fold molar excess of sodium hypochlorite at $\mathrm{pH} 6.0$ until optimal conversion of the native lipid was achieved (between 15 and $50 \mathrm{~min}$, depending on the lipid used). Excess hypochlorite was removed by passing the incubation mixture through reverse phase Sep-pak cartridges (Waters, UK) for phospholipids or normal phase cartridges for fatty acids. The columns were washed with water followed by methanol, and lipids were eluted with 1:1 methanol/chloroform followed by $100 \%$ chloroform. The organic solvent was removed under a stream of nitrogen and the lipid chlorohydrins were reconstituted in HBSS and filtered through a 0.2 micron gamma-sterilised filter prior to addition to the cells.

Analysis of chlorohydrins. The conversion of native lipids to chlorohydrins was monitored by electrospray mass spectrometry (ES-MS). One microlitre aliquots were removed and diluted 200-fold with 71:5:7 (by vol.) methanol/hexane/0.1 M ammonium acetate. ES-MS was carried out on Platform (VG) or LCQ-Duo (Finnigan) mass spectrometers in positive ion mode by direct infusion. A spectrum in the range $650-1050 \mathrm{~m} / \mathrm{z}$ was obtained for phospholipids and 200-600 m/z for fatty acids, and both loss of the native lipids and appearance of chlorohydrins at multiples of $+52 /+54 \mathrm{~m} / \mathrm{z}$ was monitored as described previously (Jerlich et al., 2000).

Analysis of cellular ATP levels for viability. U937 cells were cultured at $37^{\circ} \mathrm{C}$ in RPMI-1640 medium containing $2 \mathrm{mM}$ L-glutamine and $25 \mathrm{mM}$ Hepes, and supplemented with $10 \%$ foetal calf serum, $80 \mathrm{U} / \mathrm{mL}$ penicillin, and $0.08 \mathrm{mg} / \mathrm{mL}$ strepto- 
mycin. Treatments were carried out in 96-well luminescence plates (Greiner, UK) containing $1 \times 10^{4}$ cells per well (100 $\mu \mathrm{L}$ volume). Aliquots $(100 \mu \mathrm{L})$ of the sterile chlorohydrin preparations were added to wells, and the plate was incubated at $37^{\circ} \mathrm{C}$ in a humidified atmosphere with $95 \% \mathrm{O}_{2}$ and $5 \% \mathrm{CO}_{2}$ for $24 \mathrm{~h}$. At the end of this period, the cellular ATP levels were determined by the CellTitre-Glo ${ }^{\mathrm{TM}}$ Luminescence assay (Promega), as described previously (Dever et al., 2003). The results are expressed as a percentage of control viability, to allow comparison between individual experiments.

Caspase- 3 assays. Caspase- 3 activity was measured by a colorimetric assay based on the hydrolysis of acetyl-Asp-Glu-Val-Asp p-nitroaniline (Ac-DEVD-pNA) to release $p$-nitroaniline ( $\mathrm{pNA}$ ). U937 cells $\left(2 \times 10^{6}\right.$ cells in $\left.2.5 \mathrm{~mL}\right)$ were treated with phospholipid chlorohydrins. Following treatment, cells were washed with phosphate buffered saline (PBS) and then disrupted in $100 \mu \mathrm{L}$ of lysis buffer (50 mM Hepes, pH 7.5, 0.1\% Chaps, $1 \mathrm{mM}$ dithiothreitol, $0.1 \mathrm{mM}$ EDTA, 0.1\% Triton X-100, 0.5 $\mathrm{mM}$ PMSF, $1 \mu \mathrm{g} / \mathrm{mL}$ aprotinin, $10 \mu \mathrm{M}$ leupeptin, 1 $\mu \mathrm{M}$ pepstatin) by $15 \mathrm{~min}$ incubation on ice, $15 \mathrm{~min}$ sonication, and freeze-thawing. The cellular extract was clarified by centrifugation at $10000 \times g$ at $4^{\circ} \mathrm{C}$ and $25 \mu \mathrm{L}$ were used per assay in 96-well plates. Ac-DEVD-pNA was prepared in assay buffer (50 mM Hepes, pH 7.5, $100 \mathrm{mM} \mathrm{NaCl}, 10$ mM DTT, 1 mM EDTA, 10\% glycerol, $0.5 \mathrm{mM}$ PMSF, $1 \mu \mathrm{g} / \mathrm{mL}$ aprotinin, $10 \mu \mathrm{M}$ leupeptin, $1 \mu \mathrm{M}$ pepstatin) and used at a final concentration of $200 \mu \mathrm{M}$ in a total assay volume of $200 \mu \mathrm{L} /$ well. Selected wells containing cell extract were also pre-treated with the specific caspase-3 inhibitor Ac-DEVD-CHO for 30 $\min$ at $10 \mu \mathrm{M}$.

Leukocyte isolation and radiolabelling. C57Bl/6 (18-24 g) mice were euthanized by $\mathrm{CO}_{2}$ asphyxiation. Spleens were removed and disrupted over a $200 \mu \mathrm{m}$ mesh (Cadisch Ltd) into $3 \mathrm{~mL}$ of RPMI-1640 medium (Dutch Modification: Invitrogen Ltd, UK) containing 10\% foetal calf serum (Invitrogen). The resulting cell suspensions were passed through a $200 \mu \mathrm{m}$ mesh and centrifuged at $125 \mathrm{~g}$ for $10 \mathrm{~min}$. The supernatants were removed, and the pellets containing the cells were agitated with $4 \mathrm{~mL}$ of distilled water for $30 \mathrm{~s}$ to lyse erythrocytes; $4 \mathrm{~mL}$ of $1.8 \% \mathrm{NaCl}$ were then added, to maintain an isotonic solution, and the leukocyte suspensions were passed through a $200 \mu \mathrm{m}$ mesh and centrifuged. The resulting cell pellets were re-suspended to a final density of $1 \times 10^{6}$ cells per $\mathrm{mL}$. One millilitre of the re-suspended leukocytes was labelled for $1 \mathrm{~h}$ at $37^{\circ} \mathrm{C}$ in a humidified chamber with $5 \mu \mathrm{L}(185 \mathrm{kBq})$ of ${ }^{51} \mathrm{Cr}$ (as $\mathrm{Na}_{2} \mathrm{CrO}_{4}$; Amersham Biosciences, UK). The cells were washed twice with RPMI and re-suspended in RPMI to $1 \times 10^{6}$ cells per $\mathrm{mL}$.
Artery segment preparation and leukocyte adhesion. Homologous aortic trees from the euthanized C57Bl/6 mice were removed and cut into three segments (aortic arch, thoracic aorta and abdominal aorta). Each segment was pinned out luminal-side up onto a Sylgard block (Dow Corning, Germany) before placing in a humidified chamber at $37^{\circ} \mathrm{C}$, and incubating with RPMI-medium or $25 \mu \mathrm{M}$ SOPC chlorohydrin for 1, 2 or $4 \mathrm{~h}$. The segments were washed with RPMI before addition of $5 \mu \mathrm{L}$ aliquots of ${ }^{51} \mathrm{Cr}$ labelled cells to the artery segments and incubation for $30 \mathrm{~min}$. The segments were then washed again with RPMI, transferred into microtubes and assayed for ${ }^{51} \mathrm{Cr}$ on a gamma counter (Cobra ${ }^{\mathrm{TM}}$ Auto-gamma ${ }^{\circledR}$, Packard, Canberra Company, UK). Microtubes containing $5 \mu \mathrm{L}$ aliquots of labelled and unlabelled cells were also included in the counting process, to allow calculation of leukocyte adhesion as a percentage of the total radioactivity added to the tissue segments.

Following the adhesion assay, tissue samples were fixed in $4 \%$ formaldehyde in saline, washed in PBS before dehydration through graded alcohols and HistoClear (Fisher, UK), and embedded in paraffin wax. Sections (4 microns) were cut and mounted on glass slides for haematoxylin and eosin staining.

Statistical analysis. Multiple group comparisons for percentage splenocyte adhesion were performed using One-way ANOVA and Tukey's Post-Hoc test. For analysis of data from caspase-3 assays and ATP levels, a Student's t-test was used to compare native versus chlorohydrin treatments, and One-way ANOVA was used for comparison of treatment concentrations versus control $(0 \mu \mathrm{M}$ lipid or chlorohydrin).

\section{RESULTS}

The formation of chlorohydrins of the phospholipids and fatty acids was monitored using direct infusion electrospray mass spectrometry in positive ion mode. The spectra of the chlorohydrin preparations of stearoyl-oleoyl phosphatidylcholine (SOPC), stearoyl-linoleoyl phosphatidylcholine (SLPC) and stearoyl-arachidonoyl phosphatidylcholine (SAPC) were essentially as reported previously (Dever et al., 2003), and showed nearly complete conversion of the native lipid to the chlorohydrin for SOPC and SLPC, and approx. 50\% conversion for SAPC (not shown). Likewise with the fatty acid chlorohydrins, it was found that oleic acid had undergone almost complete conversion to the chlorohydrin form. Linoleic acid had undergone approx. $80 \%$ conversion to chlorohydrins with the mono-chlorohydrin predominating but some bis-chlorohydrin also present. With arachidonic acid, as with SAPC, a less complete 
conversion of approx. $60 \%$ to multiple chlorohydrin forms was achieved. More extensive conversion was not attempted, in order to avoid the formation of lysolipids, which has been reported previously for the arachidonate moiety (Panasenko et al., 2003). The mono-chlorohydrin of arachidonic acid was the major product, but bis-, tris-, and tetra-chlorohydrins with various mixtures of ${ }^{35} \mathrm{Cl}$ and ${ }^{37} \mathrm{Cl}$ isotope ratios were also found (not shown).

Cultured myeloid cells were incubated with both native lipids and the chlorohydrin preparations for $24 \mathrm{~h}$, and the cellular ATP levels were then determined (Fig. 1). Panels A, C, and E show the effect of the phospholipid chlorohydrins on U937 cells, while
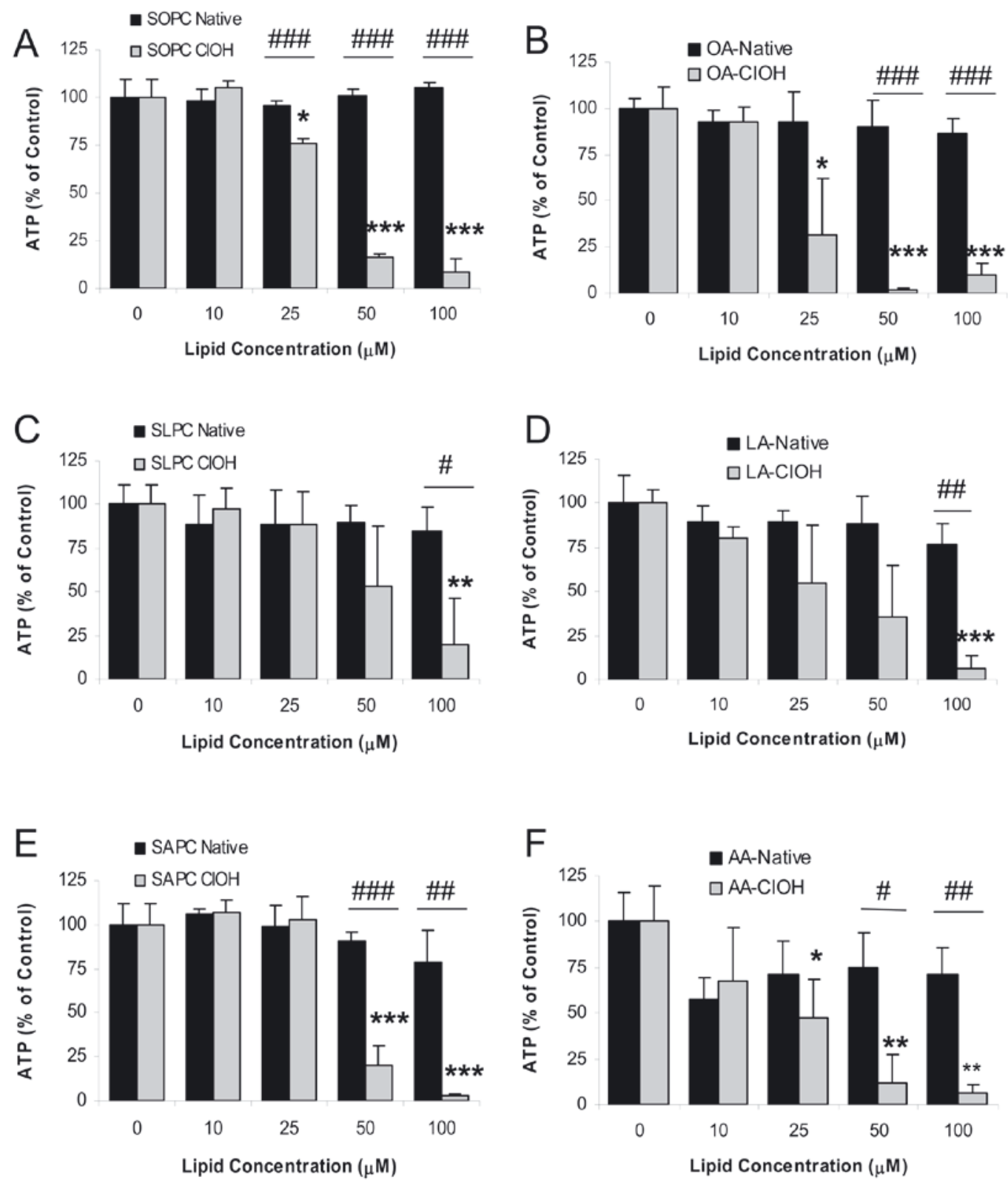

Figure 1. Effect of fatty acid and phospholipid chlorohydrins on ATP levels.

U937 cells were incubated for $24 \mathrm{~h}$ in RPMI-1640 medium containing chlorohydrins at the concentrations indicated in the graphs. Following treatment, the cellular ATP level was determined using luciferin-luciferase in a bioluminescent assay, and the percentage ATP level of the cells was calculated by comparison with untreated cells. In each panel the dark bars show treatment with native lipid, and light bars show treatment with the corresponding chlorohydrin. A) Stearoyloleoyl phosphatidylcholine; B) oleic acid; C) stearoyl-linoleoyl phosphatidylcholine; D) linoleic acid; E) stearoyl-arachidonoyl phosphatidylcholine; F) arachidonic acid. The data are the average of 3 separate experiments each carried out in triplicate, and the error bars correspond to 1 standard deviation. Significant differences compared to control (0 $\mathrm{mM})$ are shown by ${ }^{*}$ and differences compared to native lipid are shown by \#, where 1 symbol corresponds to $P<0.05,2$ symbols corresponds to $P<0.01$, and 3 symbols corresponds to $P<0.001$. 
panels B, D, and F show the effect of the fatty acid chlorohydrins on these cells. It can be seen that all of the lipid chlorohydrin treatments caused depletion of cellular ATP compared to control cells incubated with RPMI medium only, and also compared to cells treated with an equivalent concentration of unmodified lipid. It appeared that the free fatty acid chlorohydrins caused slightly greater depletion of ATP than the corresponding phospholipid chlorohydrins: this was significant for oleic acid versus SOPC at $25 \mu \mathrm{M}(P=0.004)$ and $50 \mu \mathrm{M}(P=0.01)$, but there were no significant differences for linoleic acid versus SLPC or arachidonic acid versus SAPC, though the latter just failed to reach significance at $25 \mu \mathrm{M}$ $(P=0.09)$. Both the free form and esterified forms of oleic acid appeared to cause the greatest ATP depletion, followed by the free and esterified forms of arachidonic acid, with linoleic acid in either form having the least effect on the cellular ATP. However, it should be noted that the conversion of SAPC and


Figure 2. Effect of phospholipid chlorohydrins on caspase- 3 activity.

U937 cells were incubated for $24 \mathrm{~h}$ in medium containing the chlorohydrins. The caspase- 3 activity was assayed in cell extracts by measuring absorbance at $405 \mathrm{~nm}$ corresponding to the release of $p$-nitroaniline from acetyl-AspGlu-Val-Asp p-nitroaniline (Ac-DEVD-pNA). Pre-treatment with the specific caspase-3 inhibitor Ac-DEVD-CHO was for $30 \mathrm{~min}$ at $10 \mu \mathrm{M}$. Controls correspond to cells treated with medium only. A) Stearoyl-oleoyl phosphatidylcholine chlorohydrin $(\mathrm{n}=4)$, and B) stearoyl-arachidonoyl phosphatidylcholine chlorohydrin $(n=2)$. Error bars correspond to 1 standard deviation. Significant differences are relative to control $(0 \mathrm{mM})$, where * corresponds to $P<0.05$, ** to $P<0.01$, and $* * *$ to $P<0.001$. arachidonic acid to chlorohydrins was not as complete as the other two lipids, and consequently the real effects of SAPC chlorohydrin and arachidonic acid chlorohydrin are slightly greater than is apparent from the graph. It was noted that treatment with unmodified SAPC also caused a significant loss of ATP, in agreement with previous observations (Dever et al., 2003); this effect was less pronounced with free arachidonic acid.

To investigate whether apoptosis might contribute to the toxicity observed with the chlorohydrins, caspase-3 activation was monitored in U937 cells incubated with SOPC chlorohydrin or SAPC chlorohydrin for $24 \mathrm{~h}$ (Fig. 2). It was found with both lipids that incubation with $25 \mu \mathrm{M}$ chlorohydrin, the lowest concentration tested in this assay, caused a significant increase in caspase-3 activity (approx. $100-150 \%$ increase). Increasing the chlorohydrin concentration further resulted in a decrease in caspase-3 activity compared to $25 \mu \mathrm{M}$. Inclusion of the specific caspase-3 inhibitor Ac-DEVD-CHO in the assay resulted in a substantial abrogation of caspase- 3 activation.

SOPC chlorohydrin was then selected for further studies of more physiological effects of chlorohydrin using an ex-vivo model of leukocyte-arterial adhesion as described previously (Lim et al., 2006; Dever et al., 2006). Adhesion of splenocytes to the endothelial surface could be visualized by micrographs (Fig. 3A) and was quantitated by ${ }^{51} \mathrm{Cr}$-labelled splenocyte-dependent radioactivity of the arterial segments. It was found that incubation of mouse artery segments with SOPC chlorohydrin caused significant enhancement of splenocyte adhesion to the endothelium (Fig. 3B). Incubation of artery segments with $25 \mu \mathrm{M}$ SOPC chlorohydrin for 10 min was not long enough to stimulate increased adhesion of radiolabelled splenocytes, but longer incubation times $(1-4 \mathrm{~h})$ caused approximately a 3-fold increase in adhesion of splenocytes to aortic, thoracic and abdominal artery segments. The increase in all segments was maximal or nearly maximal at $1 \mathrm{~h}$; extending the incubation period to 2 or $4 \mathrm{~h}$ did not greatly enhance the splenocyte adhesion. Incubation with unmodified SOPC did not cause any increase in adhesion (not shown).

\section{DISCUSSION}

It is becoming increasingly accepted that $\mathrm{HOCl}$-modified LDL is important in atherosclerosis, but the contributions of lipid modifications versus protein modifications are not completely understood. As $\mathrm{HOCl}$ treatment of LDL generates chlorohydrins, these could contribute to adverse effects of $\mathrm{HOCl}-$ LDL at a cellular and tissue level. The first finding 

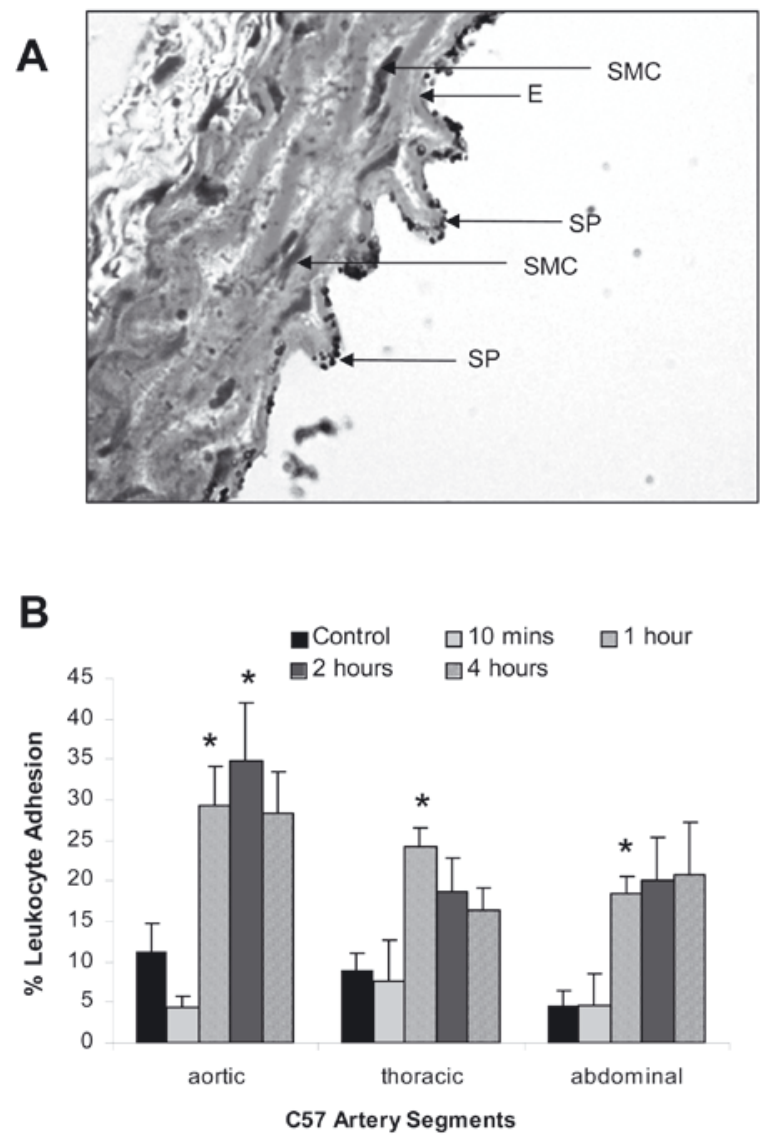

Figure 3. Effect of SOPC chlorohydrin on splenocyte-arterial adhesion.

C57Bl/6 artery segments were incubated with $25 \mu \mathrm{M}$ stearoyl-oleoyl phosphatidylcholine chlorohydrin before addition of ${ }^{51} \mathrm{Cr}$-labelled splenocytes for $30 \mathrm{~min}$. A) Micrograph of an artery segment stained with haematoxylin and eosin showing adherent splenocytes (SP), endothelium (E), and smooth muscle cells (SMC). B) The adhesion of splenocytes was quantitated by measurement of segment radioactivity and the results are shown as percentage of the total radioactivity added per segment. The segments were incubated with chlorohydrin for $0 \mathrm{~min}$ (control, $\mathrm{n}=11$ ), $10 \min (\mathrm{n}=5), 1 \mathrm{~h}(\mathrm{n}=10), 2 \mathrm{~h}(\mathrm{n}=8)$ or $4 \mathrm{~h}(\mathrm{n}=10)$. Error bars are 1 standard error of the mean and *indicates $P<0.05$ compared to control.

of this study was that both phospholipid and fatty acid chlorohydrins caused similar depletion of cellular ATP levels in cultured myeloid U937 cells. The loss of cellular ATP indicates that the cells are stressed and that loss of viability is occurring, which is in agreement with previous studies that have shown toxic effects of fatty acid or cholesterol halohydrins on erythrocytes and endothelial cells (Carr et al., 1997; Vissers et al., 2001). However, measurement of cellular ATP levels cannot distinguish between apoptosis and necrosis, so the effect of SOPC- and SAPC-chlorohydrins on cellular caspase3 activity was also assayed to investigate whether a lipid chlorohydrin might be able to induce apoptosis. Caspase-3 activation was evident at lower treat- ment severity than loss of ATP and diminished as the treatment concentration increased, consistent with the idea that the mode of cell death is dosedependent, with lower doses causing apoptosis and higher doses diminishing apoptosis but increasing necrosis (Buttke \& Sandstrom, 1994; Vayssier et al., 1998; Vissers et al., 1999). Similar concentrations (10 $\mu \mathrm{M})$ of palmitoyl-arachidonoyl phosphatidylcholine oxidation products have previously been found to induce apoptosis and caspase-3 activation in arterial smooth muscle cells (Loidl et al., 2003), via activation of acid sphingomyelinase. Possibly the chlorinated oxidation products of phospholipids could act by a similar mechanism.

Our results suggest that lipid chlorohydrins may have more complex cellular effects than previously thought. Earlier studies have mainly focused on membrane disruption as a mechanism for toxicity; as chlorohydrins are more polar than native lipids, their formation within membrane or subsequent incorporation was thought to disrupt the lipid bilayer structure, and result in toxicity simply through physical effects (Carr et al., 1997). In studies on human endothelial cells, the mechanism of cell death was described as necrotic rather than apoptotic, and similar to that observed with higher doses of direct $\mathrm{HOCl}$ treatment (Vissers et al., 2001), although lower doses of $\mathrm{HOCl}$ induced apoptosis (Vissers et al., 1999). However, this may relate to the lipid chlorohydrin concentration used by Vissers et al. (2001) when observing morphological changes, of which the lowest tested was $37.5 \mu \mathrm{M}$.

The other major finding of the study was that treatment of arterial segments with SOPC chlorohydrin induced a significant increase in splenocyte adhesion within one hour. The treatment of arterial segments was carried out at a low chlorohydrin concentration $(25 \mu \mathrm{M})$ and over relatively short time periods, as previously we have found that toxic effects of phospholipid chlorohydrins only became apparent after $6 \mathrm{~h}$ (Dever et al., 2003). This was important to ensure that the increased adhesion observed following chlorohydrin treatment was not simply due to cell death and release of cell components that could be pro-inflammatory. Thus it appears that phospholipid chlorohydrin can cause a pro-inflammatory effect comparable to that observed with autooxidized palmitoyl-arachidonoyl phosphatidylcholine (PAPC) (Watson et al., 1997). Furthermore, the concentration that induces this effect is similar to the concentrations of PAPC oxidation products, such as palmitoyl-oxovaleroyl phosphatidylcholine and hydroxy alkenal derivatives of phosphatidylcholines, which have also been found to cause adhesion of monocytes to human aortic endothelial monolayers, and increased production of MCP-1 and IL-8 (Subbanagounder et al., 2002b). This further supports the 
hypothesis that chlorohydrins, in addition to causing necrosis at high concentrations, may act on cells in more subtle ways to alter cell functions. The mechanism of chlorohydrin-induced adhesion to arterial segments is currently unknown, and further study is warranted to investigate this.

This study has presented the first evidence that phospholipid chlorohydrins can induce inflammatory cell-endothelial adhesion, and therefore that $\mathrm{HOCl}$-modification of the phospholipid moiety of LDL may contribute to the pro-inflammatory and pro-atherogenic effects of HOCl-LDL that have been reported previously.

\section{Acknowledgements}

The research was funded by the University of Strathclyde and Tenovus-Scotland (S00/4).

\section{REFERENCES}

Bergt C, Pennathur S, Fu X, Byun J, O'Brien K, McDonanld TO, Singh P, Anantharamaiah GM, Chait A, Brunzell J, Geary RL, Oram JF, Heinecke JW (2004) The myeloperoxidase product hypochlorous acid oxidizes HDL in the human artery wall and impairs ABCA-1-dependent cholesterol transport. Proc Natl Acad Sci USA 101: 13032-13037.

Brennan ML, Hazen SL (2003) Emerging role of myeloperoxidase and oxidant stress markers in cardiovascular risk assessment. Curr Opin Lipidol 14: 353-359.

Buttke TM, Sandstrom PA (1994) Oxidative stress as a mediator of apoptosis. Immunol Today 15: 7-10.

Carr AC, Vissers MC, Domigan NM, Winterbourn CC (1997) Modification of red cell membrane lipids by hypochlorous acid and haemolysis by preformed lipid chlorohydrins. Redox Rep 3: 263-271.

Chisolm GM, Steinberg D (2000) The oxidative modification hypothesis of atherogenesis: an overview. Free Radic Biol Med 28: 1815-1826.

Daugherty A, Rateri DL, Dunn JL, Heinecke JW (1994) Myeloperoxidase, a catalyst for lipoprotein oxidation, is expressed in human atherosclerotic lesions. J Clin Invest 94: 437-444.

Dever G, Stewart LJ, Pitt AR, Spickett CM (2003) Phospholipid chlorohydrins cause ATP depletion and toxicity to human myeloid cells. FEBS Letts 540: 245-250.

Dever G, Spickett CM, Kennedy S, Rush C, Tennant G, Monopoli A, Wainwright CL (2006) The NO-donating pravastatin derivative (NCX 6550) reduces splenocyte adhesion and ROS generation in normal and atherosclerotic mice. J Pharmacol Exp Ther Epub 27 Sept.

Hazell LJ, Arnold L, Flowers D, Waeg G, Malle E, Stocker R (1996) Presence of hypochlorite-modified proteins in human atherosclerotic lesions. J Clin Invest 97: 15351544.

Hazen SL, Heinecke JW (1997) 3-Chlorotyrosine, a specific marker of myeloperoxidase-catalysed oxidation, is markedly elevated in low density lipoprotein isolated from human atherosclerotic intima. J Clin Invest 99: 2075-2081.

Iwase $\mathrm{H}$, Yamada $\mathrm{Y}$, Uemura H, Nakaya H, Takatori T, Nagao M, Iwadate K (1997) Effect of monochlorohy- drins of linoleic acid on guinea-pig cardiac papillary muscles. Biochem Biophys Res Comm 231: 295-298.

Jerlich A, Pitt AR, Schaur RJ, Spickett CM (2000) Pathways of phospholipid oxidation by $\mathrm{HOCl}$ in human LDL detected by LC-MS. Free Radic Biol Med 28: 673-682.

Katrantzis M, Baker M, Handley CJ, Lowther DA (1991) The oxidant hypochlorite $\left(\mathrm{OCl}^{-}\right)$, a product of the myeloperoxidase system, degrades articular cartilage proteoglycan aggregate. Free Radic Biol Med 10: 101-109.

Kopprasch S, Leonhardt W, Pietzsch J, Kuhne H (1998) Hypochlorite-modified low-density lipoprotein stimulates human polymorphonuclear leukocytes for enhanced production of reactive oxygen metabolites, enzyme secretion, and adhesion to endothelial cells. Atherosclerosis 136: 315-324.

Kopprasch S, Pietzsch J, Westendorf T, Kruse HJ, Grassler J (2004) The pivotal role of scavenger receptor CD36 and phagocyte-derived oxidants in oxidized low density lipoprotein-induced adhesion to endothelial cells. Int J Biochem Cell Biol 36: 460-471.

Lim SY, Tennant GM, Kennedy S, Wainwright CL, Kane KA (2006) Activation of mouse protease-activated receptor-2 induces lymphocyte adhesion and reactive oxygen species generation. Br J Pharmacol 149: 591-599.

Madamanchi N, Vendrov A, Runge M (2005) Oxidative stress and cardiovascular disease. Arterioscler Thromb Vasc Biol 25: 29-38.

Nguyen-Khoa T, Massy ZA, Witko-Sarsat V, Canteloup S, Kebede M, Lacour B, Drueke T, Descamps-Latscha B (1999) Oxidised LDL induces macrophage respiratory burst via its protein moiety: a novel pathway in atherogenesis? Biochem Biophys Res Commun 263: 804-809.

Panasenko OM, Spalteholz H, Schiller J, Arnhold J (2003) Myeloperoxidase-induced formation of chlorohydrins and lysophospholipids from unsaturated phosphatidylcholines. Free Radic Biol Med 34: 553-562.

Podrez EA, Abu-Soud HM, Hazen SL (2000) Myeloperoxidase-generated oxidants and atherosclerosis. Free Radic Biol Med 28: 1717-1725.

Ross R (1993) The pathogenesis of atherosclerosis: an update: a perspective for the 90's. Nature 362: 801-809.

Spickett CM, Dever G (2005) Studies of phospholipid oxidation by electrospray mass spectrometry: from analysis in cells to biological effects. Biofactors 24: 17-31.

Subbanagounder G, Wong JW, Lee H, Faull KF, Miller E, Witztum JL, Berliner JA (2002a) Epoxyisoprostane and epoxycyclopentenone phospholipids regulate monocyte chemotactic protein-1 and interleukin-8 synthesis. J Biol Chem 277: 7271-7281.

Subbanagounder G, Deng Y, Borromeo C, Dooley AN, Berliner JA, Salomon RG (2002b) Hydroxy alkenal phospholipids regulate inflammatory functions of endothelial cells. Vasc Pharmacol 38: 201-209.

Thukkani AK, McHowat J, Hsu F-F, Brennan M-L, Hazen SL, Ford DA (2003) Identification of $\alpha$-chloro fatty aldehydes and unsaturated lysophosphatidylcholine molecular species in human atherosclerotic lesions. Circulation 108: 3128-3133.

Vayssier M, Banzet N, Francois D, Bellmann K, Polla BS (1998) Tobacco smoke induces both apoptosis and necrosis in mammalian cells: differential effects of HSP70. Am J Physiol 275: L771-779.

Vissers MC, Pullar JM, Hampton MB (1999) Hypochlorous acid causes caspase activation and apoptosis or growth arrest in human endothelial cells. Biochem J 344: 443449.

Vissers MCM, Carr AC, Winterbourn CC (2001) Fatty acid chlorohydrins and bromohydrins are cytotoxic to human endothelial cells. Redox Report 6: 49-55. 
Watson AD, Leitinger N, Navab M, Faull KF, Hörkkö S, Witztum JL, Palinski W, Schwenke D, Salomon RG, Sha W, Subbanagounder G, Fogelman AM, Berliner JA (1997) Structural identification by mass spectrometry of oxidized phospholipids in minimally oxidized low density lipoprotein that induce monocyte/endothelial interactions and evidence for their presence in vivo. $J$ Biol Chem 272: 13597-13607.

Winterbourn CC, van den Berg JJM, Roitman E, Kuypers FA (1992) Chlorohydrin formation from unsaturated fatty acids reacted with hypochlorous acid. Arch Biochem Biophys 296: 547-555.

Witztum JL, Steinberg D (1991) Role of oxidized low density lipoprotein in atherogenesis. J Clin Invest 88: 17851792.

Woenckhaus C, Kaufmann A, Bussfeld D, Gemsa D, Sprenger H, Groene H-J (1998) Hypochlorite-modified LDL: chemotactic potential and chemokine induction in human monocytes. Clin Immunol Immunopathol 86: 27-33. 